\title{
Oor eksegetiese metodes en nog wat: 'n Gesprek
}

\author{
WS Prinsloo \\ Universiteit van Pretoria
}

\begin{abstract}
On exegetical methods and all that: $\mathbf{A}$ discussion

Discussions with leading European Old Testament scholars indicate that there have been no dramatic changes in exegetical methodology during the past ten years and that no consensus has been reached in this regard. Nevertheless most scholars appear to agree that both synchronic and diachronic facets should receive proper attention in the exegetical process, and that the two may be combined in a single model. The role of the reader and the whole matter of reception theory do not seem to have received much attention from Old Testament scholars in Europe.
\end{abstract}

Soos ongeveer tien jaar gelede (Prinsloo 1979: 201-210) was dit weer eens my voorreg om met 'n aantal Europese Ou-Testamentici gesprekke te kon voer oor die vakterrein van die Ou Testament in die algemeen en die metodologie van eksegese in die besonder. Oor dié aangeleentheid kan en mag eksegete nooit uitgepraat raak nie.

Hoewel die eksegete wat hier aan die woord gestel word se werkwyse meestal goed bekend is uit hulle publikasies, was dit tog sinvol om indringende gesprekke met hulle te kon voer en pertinente vrae te kon vra. Op dié wyse is dit moontlik om sekere vergelykings te tref. Die eksegete wat hier aan die woord gestel word, is verteenwoordigend van 'n verskeidenheid van konfessionele en metodologiese invalshoeke. Natuurlik kan 'n mens nie op grond van gesprekke met enkele eksegete tot konklusies oor die algemene stand van die Ou-Testamentiese eksegese kom nie. Tog bied dit ' $n$ mens die geleentheid om sekere tendense en ontwikkelinge in die vakgebied aan te wys. Die keuse van eksegete waarmee gesprekke gevoer is, is in 'n sekere sin heel willekeurig. Die volgorde waarin die gesprekke weergegee word, dui ook nie prioriteit aan nie maar is gewoon 'n aanduiding van die kronologiese orde waarin die gesprekke plaasgevind het. Hoewel gepoog is om die 
gesprekke met die onderskeie geleerdes so 'objektief' en getrou as moontlik weer te gee, vind daar tog herinterpretasie plaas en word die eksegete deur die gesprekvoerder 'gelees' sodat 'n mens nie volkome aan subjektiwiteit kan ontkom nie:

Dr Eep Talstra (Vrije Universiteit Amsterdam) ag dit noodsaaklik dat die sinkroniese en diakroniese aspekte saam in een eksegetiese model gebruik moet word. Dit is vir hom dus nie ' $n$ kwessie van die een of die ander nie, maar albei aspekte moet aan die orde kom. Hy staan dus 'n komplementère benadering voor. Talstra het juis in sy proefskrif (Talstra 1987) dié benadering probeer illustreer. Hoewel Talstra die sinkroniese en diakroniese aspekte van eweveel belang ag om die teks te verstaan, oordeel hy dat die sinkroniese werk die diakroniese moet voorafgaan. Die sinkroniese analise is juis 'n hulpmiddel om die groei van die teks te help rekonstrueer en om 'nate' en 'lae' in die teks te identifiseer. In die sinkroniese analise behoort dit veral te gaan oor morfologiese en sintaktiese sake. Talstra ag 'n aktante analise ook van groot belang wanneer daar met narratiewe stof gewerk word (Talstra 1987: $118 \mathrm{vv}$ ). 'n Teks behoort dus twee keer geanaliseer te word: Eers sinkronies, stilisties en daarna diakronies, redaksie-krities. Talstra is ook deel van 'n span navorsers, bekend as Werkgroep Informatica, by die Vrije Universiteit wat reeds die hele Ou Testament met behulp van 'n rekenaarprogram morfologies en sintakties ontleed het (Talstra 1981, 1983a, 1983b, 1989). Hoewel Talstra hom op die oomblik nie eintlik met die teologie van die Ou Testament besig hou nie, is hy van oordeel dat hierdie analises tog ook uiteindelik relevant vir die boodskap en die teologie van die Ou Testament is.

Prof Martin J Mulder, wat as promotor opgetree het vir die proefskrif van Talstra, het aan die begin van 1989 as hoogleraar van die Rijksuniversiteit te Leiden geëmeriteer. Mulder stem basies met Talstra saam oor die verhouding sinkronie-diakronie. In die praktiese beoefening van die eksegese werk hy nie struktureel nie, maar soos wat hy dit noem, eerder grammaties-histories. In sy resente kommentaar op 1 Konings 1-7 (Mulder 1987) val die klem op die filologiese, godsdienshistoriese en literêre aspekte (vgl ook Mulder 1989). Dit blyk uit die gesprekke met dié Nederlandse eksegete dat die besinning rondom die resepsieteorieë nog nie eintlik daar posgevat het nie.

Dr Jesper Hogenhaven van die Universiteit van Kopenhagen (Denemarke) het onlangs 'n belangwekkende boek oor die teologie van die Ou Testament (Problems and prospects of Old Testament Theology) gepubliseer (Høgenhaven 1987). Hy is 'n leerling van die bekende Skandinawiese geleerde Eduard Nielsen en konsentreer 
veral op die boek Jesaja (Høgenhaven 1988). Høgenhaven is van mening dat die sinkroniese en diakroniese aspekte van die eksegese twee aparte paradigmas is wat nie gelyktydig op 'n teks toegepas behoort te word nie. Albei dié sake is egter nodig om die teks te verstaan en moet komplementêr gebruik word. In die Skandinawiese lande wat 'n tyd gelede moontlik onder een noemer tuisgebring sou kon word, naamlik die tradisie-historiese benadering (met die klem op mondelinge oorlewering), is daar nou so 'n verskeidenheid van benaderings dat dit nie meer moontlik is om hulle onder een noemer tuis te bring nie. Die beoefenaars van die tradisiehistoriese benadering is tans ook minder polemies en meer tolerant teenoor ander eksegetiese modelle. Høgenhaven is van mening dat daar in die Skandinawiese lande oor die algemeen gesproke tog ' $n$ beweging is in die rigting van ' $n$ meer sinkronies-literêre benadering.

Prof Klaus Koch van die Universität Hamburg (Wes-Duitsland), 'n bekende OuTestamentikus wat reeds baie gepubliseer het, is 'n leerling van Von Rad (Koch 1976, 1981, 1986). Hy is van mening dat sy boeke oor die profete (Koch 1978, 1980) te konserwatief is na die Duitsers se smaak! Oor die eksegetiese metodologie sê hy dat die kanoniese benadering van Childs neig om a-histories te wees en nie genoeg van die groei van die kanon maak nie. lemand soos JP Fokkelman maak met sy metode historiese vrae eintlik oorbodig. By dié geleerdes in Duitsland wat 'rein historisch' werk (bv die 'Göttinger-Schüle', by name Smend en Perlitt) het die literêr-kritiese metode, volgens Koch, doel op sigself geword om maar net redaksielaag op redaksielaag te rekonstrueer. Elkeen bou as 't ware by wyse van spreke aan sy eie Pentateug. Koch se benadering is ook dat 'n mens moet begin met die 'Endgestalt' van die teks en dit sinkronies moet benader. Soos wat 'n argeologiese uitgrawing met ' $n$ analise van die boonste laag moet begin, so moet die eksegese ook met die 'Endgestalt' van die teks begin (Koch 1987: 467). As die eksegeet egter tot 'nachprüfbaren' resultate wil kom, sal hy ongetwyfeld ook die diakroniese fasette in sy metodologie moet invoer. Wie dink dat hy tot bevredigende resultate kan kom sonder die historiese gesigspunt verkeer dus onder 'n illusie (vgl Koch 1981: $318 \mathrm{vv}$ ). Daar moet dus ook na die groei van die teks (veral na die oorlewering van die tradisies) gekyk word. Koch meen ook dat 'n mens by die skrywe van 'n teologie van die Ou Testament met die tradisiestrominge moet werk. 'n Ou Testament teologie moet verder ook uitloop op 'n Biblische Theologie. So 'n Ou Testament teologie behoort ook 'n gesprek met die Nuwe Testament en die Judaisme in te sluit. Dit blyk dat die invloed van die 'Konstanz-Schüle' en die debat rondom die resepsieteorie nog nie eintlik vir Koch relevant geword het nie. 
Prof Oswaldt Loretz is 'n Rooms-Katolieke geleerde aan die Universität Münster. Hy spesialiseer in die Ugaritologie en in die Psalmnavorsing (Loretz 1971, 1974, 1975, 1979, 1986, 1987, 1988). Om te onderskei tussen sinkroniese en diakroniese werk is vir hom 'n valse onderskeiding. Beide dié fasette moet gelyktydig aan die orde kom. Die tradisieproses waarlangs 'n teks tot stand kom is baie belangrik. Om van die 'Endgestalt' van die teks te praat is vir Loretz 'n valse probleemstelling want 'n teks is die resultaat van 'n interpretasieproses. Om dié rede het Loretz, om dit eufemisties te stel, nie 'n hoë waardering vir die kanoniese benadering van byvoorbeeld Childs en Rendtorff nie. Ook die literatuurwetenskaplike metode van Richter spreek hom geensins aan nie. Volgens Loretz werk Richter met die positiwistiese beginsel van die natuurwetenskappe omdat hy 'nachprufbar' wil werk. Oor een van Richter se studente (Wehrle) se proefskrif oor Obadja maak Loretz byvoorbeeld die volgende opmerking: 'Die hier angewandte linguistische Methode beruht auf höchst problematischen Prämissen, die kaum als exakı wissenschaftlich zu bezeichnen sind' (Loretz 1989: 12). Sowel Rendtorff as Richter gaan volgens Loretz, met ideologiese en dogmatiese vooronderstellings na die teks toe. Loretz meen dat Wellhausen, Gunkel en Mowinckel eintlik die enigste Ou-Testamentiese geleerdes is wat die afgelope eeu werklik iets nuuts gesê het. Selfs Von Rad het nie eintlik iets nuuts bygedra nie. Vir Loretz gaan dit dus om die rekonstruksie van die tradisie- en interpretasieproses van die teks. Hy werk met 'n sogenaamde kolometriese analise om dié proses te rekonstrueer (Loretz 1975, 1986). Sy kriterium om die Hebreeuse poësie te analiseer en die interpretasieproses te rekonstrueer, vind hy in die Ugaritiese poësie omdat laasgenoemde uit dieselfde tradisie as die Hebreeuse poësie kom. Dit is belangrik om daarop te wys dat Loretz'n leerling van Dahood is. Dahood het natuurlik ook in sy bekende kommentare oor die psalms Ugarities as vergelykingsmateriaal gebruik om die Psalms mee te verklaar. Hoewel Loretz anders as Dahood die Ugarities nie etimologies aanwend nie - maar wel kolometries - kan dit nie weggeredeneer word nie dat die beginsel om Ugarities as vergelykingsgrond te gebruik tog van Dahood afkomstig is. Of Loretz met dié benadering ontkom aan positiwisme en dogmatisme (dit waarvan hy ander eksegete beskuldig) is te betwyfel.

Prof Walter Beyerlin doseer ook soos Loretz aan die Universität Münster, maar hy is 'n Lutheraan. Beyerlin is 'n leerling van Elliger en het hoofsaaklik in Tübingen studeer. Beyerlin beskou homself as 'n histories-kritiese geleerde en maak nie so 'n groot verskil tussen sinkroniese en diakroniese werk nie. Hy konsentreer in sy navorsing op die Psalms. Kenmerkend van sy werkwyse is dat hy baie uitvoerig werk en gewoonlik 'n hele monografie aan 'n enkele Psalm wy (Beyerlin 1977, 1982, 
1985a, 1985b). In sy werk oor die Psalms begin hy met die 'Endgestalt' van die teks en gee uitvoerige aandag aan byvoorbeeld stilistiese sake. Hy doen dit egter hoofsaaklik om by die 'primêre teks', dit beteken dié deel wat deur die oorspronklike skrywer of digter geskryf is, uit te kom. Die latere redaksionele byvoeginge is egter nie onbelangrik of sonder sin nie. Vir Beyerlin is die tradisiegeskiedenis van 'n teks uiters belangrik en hy gee in sy Psalmnavorsing ook baie aandag daaraan. Hy probeer ook telkens om wedersydse beïnvloeding tussen die Psalms en byvoorbeeld die profetiese geskrifte en die wysheidsliteratuur aan te toon. 'n Aspek van die eksegetiese proses waaroor Beyerlin ietwat huiwerig voel, is die bepaling van die Gattung. Hy reken dat ons nog nie regtig 'n greep het op dié saak nie. Soos reeds aangetoon, lewer Beyerlin gedetailleerde werk oor die Psalms. Hy is gevolglik van mening dat 'n Psalmkommentaar soos dié van $\mathrm{H}-\mathrm{J}$ Kraus te oppervlakkig is. Om dié rede dink Beyerlin dat dit feitlik onmoontlik is vir een eksegeet om 'n kommentaar op die hele Psalmboek te skryf. Desgelyks is dit onmoontlik om 'n samevattende teologie van die Ou Testament te skryf. Hy sou eerder voorkeur gee aan 'n tradisie-historiese benadering soos dié van Werner $\mathrm{H}$ Schmidt. (Alttestamentlicher Glaube in seiner Geschichte). Indien hy 'n handboek vir sy studente sou moes kies om hulle in te lei in die metodologie van eksegese, sou hy vanselfsprekend eerder'n handboek kies soos dié van Barth en Steck (Barth \& Steck 1977) wat historieskrities georiënteerd is, as 'n boek soos dié van Richter (1971) wat literatuurwetenskaplik werk.

Prof Paul Maiberger is 'n Rooms-Katolieke Ou-Testamentikus aan die Universität Passau, een van die jongste universiteite in Wes-Duitsland. Hy konsentreer tans in sy navorsing hoofsaaklik op die Sinai-probleem (Maiberger 1984), maar het tog ook in die jongste verlede sinvolle bydraes oor die Psalms gelewer (Maiberger 1988) Volgens Maiberger moet 'n mens eers diakronies met 'n teks werk. Dit is eers wanneer jy die groei van' $n$ teks gerekonstrueer het en die verskillende redaksionele bywerkings bepaal het dat jy die teks in sy finale gestalte verstaan. Om die teks te verstaan, moet jy weet waar die teks vandaan kom. Tog erken Maiberger dat die rekonstruksie van die groeiproses van 'n teks 'n baie hipotetiese saak is. Vanselfsprekend ag hy die Literaturkritik van groot belang. Hy het ironies genoeg hoë waardering vir die benadering van Richter. Dit is egter slegs een aspek van Richter se metode wat Maiberger sterk aanspreek en dit is sy Literarkritik. Dit lyk egter of hy ook wat dié aspek betref, vir Richter verstaan soos wat hy hom graag wil verstaan. Maiberger erken dat eksegete in Duitsland te min aandag aan die Endgestalt van die teks gee. Oor die verhouding Ou Testament/Nuwe Testament sê Maiberger dat die Ou Testament 'n oop boek is en dat die Ou Testament sy ware betekenis in 
Christus vind en 'n voorbereiding is vir die Nuwe Testament. Nogtans interpreteer Maiberger die Ou Testament nie direk Christologies nie. Hoewel die profeet Jesaja Christus nie direk in die oog gehad het in gedeeltes soos byvoorbeeld Jesaja 7 en 9 nie, het God as die 'primêre Outeur' dit tog in die oog gehad. Dit is interessant om daarop te wys dat hoewel Maiberger histories-krities werk, hy tog in terme van die voorbeeld van Jesaja 7 en 9 neig om 'n meganiese Skrifopvatting te openbaar. Maiberger het nie veel erg aan die teologie van die Ou Testament soos wat dit tradisioneel beoefen word nie. Daar moet eerder gekyk word na die ontwikkeling dus diakronies - wat die Gottesbild in die Ou Testament vanaf politeïsme tot monoteïsme deurloop het.

Prof Siegfried Mittmann van die Biblisch-Argäologisches Institut, Universität Tübingen, hou hom hoofsaaklik met argeologie besig, maar het ook reeds belangrike bydraes op die gebied van die eksegese gelewer (Mittmann 1975, 1978, 1980). Hy werk ook histories-krities en ag die Literarkritik om dié rede van die allergrootste belang. Die Literarkritik stel hom in staat om die Grundformen van die teks te rekonstrueer. Dit is vir hom ook belangrik om na die komposisie en opbou van die Grundformen te kyk (Mittmann 1978, 1980). Mittmann is van mening dat 'n teks meestal in drie fases ontstaan het. Mittmann is 'n goeie voorbeeld van 'n historieskritiese geleerde. Hy vind geen aanklank by wat hy noem die strukturalisme van die Richterskool nie. Dié deel van die Richterskool (bv Walter Gross) wat meer grammaties werk, se resultate vind hy egter baie waardevol om vir sy eie eksegetiese werk aan te wend.

Indien ' $n$ mens na aanleiding van die bogenoemde gesprekke tot enige konklusies kan kom, sou ek die volgende samevattende opmerkings wou maak:

- Daar het die afgelope tien jaar, ten minste wat Europa betref, geen dramatiese veranderinge en ontwikkelinge ten opsigte van die metodologie van eksegese ingetree nie.

- Die eksegetiese benadering word tot 'n groot mate bepaal deur die 'skool' en die kerklike tradisie waaruit 'n eksegeet kom.

- Wat die eksegetiese metores betref, kan daar ook gesê word: 'Soveel hoofde, soveel sinne'. Dit lyk eerder asof dié situasie sal voortduur as wat daar tot konsensus gekom sal word. 
- Ten spyte van verskillende eksegetiese uitgangspunte is daar egter 'n mate van eensgesindheid daaroor dat die sinkroniese en diakroniese aspekte beide belangrik is by die interpretasieproses van 'n teks.

- Hoewel daar geen eenstemmigheid is oor die volgorde sinkronie/diakronie nie, blyk dit tog dat die meeste eksegete van mening is dat albei die fasette in een eksegetiese model geakkomodeer kan word en dat daar nie onoorkomelike paradigmatiese besware daarteen ingebring kan word nie.

* Selfs by eksegete wat histories-krities werk, blyk daar 'n groter bewuswording te wees van die teks in sy Endgestalt. Die opmerkings van Ed Noort (1989: 21) in 'n resente artikel som die situasie goed op: 'In de laatste jaren is steeds duideliker geworden, dat de vakwetenschappelijke discussie een weg zoekt tussen diachronische en synchronische benaderingen... Daarbij kwam de ontdekking, dat de uitleg van de tekst in zijn Endgestalt niet alleen een verwaarloosd gebied is, maar met name door benaderingen vanuit de literatuurwetenschap ook een kansrijke onderneming'.

- Dit blyk tog dat 'n eensydige benadering (soos die kanoniese benadering wat neig om a-histories te wees of 'n histories-kritiese benadering wat net aan die groei van die teks aandag gee) skerp kritiek van beide kante van die spektrum ontlok.

- Die besinning oor resepsieteorieë en die rol van die leser het nog nie veel ingang gevind by Europese eksegete nie.

\section{Literatuurverwysings}

BARTH, H \& STECK, OH 1977. Exegese des Alten Testaments: Leitfaden der Methodik. 7. Aufl. Neukirchen-Vluyn: Neukirchener Verlag.

BEYERLIN, W 1977. "Wir sind wie Träumende": Studien zum 126. Psalm. Stuttgart: Verlag Katholisches Bibelwerk. (SBS 89.)

BEYERLIN, W 1982. Wider die Hybris des Geistes: Studien zum 131. Psalm. Stuttgart: Verlag Katholisches Bibelwerk. (SBS 108.)

BEYERLIN, W 1985a. Weisheitlich-kultische Heilsordnung: Studien zum 15. Psalm. Neukirchen-Vluyn: Neukirchener Verlag. (Biblisch-Theologische Studien 9.) 
BEYERLIN, W 1985b. Weisheitliche Vergewisserung mit Bezug auf den Zionskult: Studien zum 125. Psalm. Göttingen: Vandenhoeck \& Ruprecht. (Orbis Biblicus et Orientalis 68.)

HØGENHAVEN, J 1987. Problems and prospects of Old Testament Theology. Sheffield: JSOT.

HØGENHAVEN, J 1988. Gott und Volk bei Jesaja: Eine Untersuchung zur Biblischen Theologie. Leiden: Brill. (Acta Theologica Danica XXIV.)

KOCH, K et al 1976. Amos: Untersucht mit den Methoden einer strukturalen Formgeschichte. Kevelaer: Butzon. (AOAT 30.)

KOCH, K 1978. Die Profeten I: Die Assyrische Zeit. Stuttgart: Kohlhammer. (Urban-Taschenbücher 280.)

KOCH, K 1980. Die Profeten II: Die Babylonisch-persische Zeit. Stuttgart: Kohlhammer. (Urban-Taschenbücher 281.)

KOCH, K 1981. Was ist Formgeschichte? Methoden der Bibelexegese. 4. Aufl. Neukirchen-Vluyn: Neukirchener Verlag.

KOCH, K 1986. Daniel. Neukirchen-Vluyn: Neukirchener Verlag. (BKAT 22.)

KOCH, K 1987. P - Kein Redaktor! Erinnerung an zwei Eckdaten der Quellenscheidung. VT 37, 446-467.

LORETZ, O 1971. Studien zur althebräischen Poesie 1. Das althebräische Liebeslied. AOAT 14/1, 55-56.

L.ORETZ, O 1974. Psalmen Studien III (Psalm 23). UF 6, 187-191.

LORETZ, O 1975. Die Analyse der ugaritischen und hebräischen Poesie mittels Stichometrie und Konsonantenerzählung. UF 7, 265-269.

LORETZ, O 1979. Die Psalmen Teil II. AOAT 207/2, 7-12.

LORETZ, O 1986. Kolometrie ugaritischer und hebräischer Poesie: Grundlagen, informationstheoretische und literaturwissenschaftliche Aspekte. $Z A W 98,249$ 266.

LORETZ, O \& KOTTSIEPER, I 1987. Colometry in Ugaritic and Biblical poetry: Introduction, illustrations and topical bibliography. Altenberge: CIS-Verlag. (Ugaritisch-Biblische Literatur 5.)

LORETZ, O 1988. Ugarit-Texte und Thronbesteigungspsalmen: Die Metamorphose des Regenspenders Baal-Jahwe. Münster: Ugarit Verlag. (Ugaritisch-Biblische Literatur 7.)

LORETZ, O 1989. Oorsigartikel: Wehrle, J 1987. Prophetie und Textanalyse. ThRv $85 / 1,12$.

MAIBERGER, P 1984. Topographische und historische Untersuchungen zum Sinaiproblem. Göttingen: Vandenhoeck. (Orbis Biblicus et Orientalis 54.) 
MAIBERGER, P 1988. Zur Problematik und Herkunft der sogenannten Fluch psalmen. TThZ 97/3, 183-216.

MITTMANN, S 1975. Deuteronomium 1: 1 - 6: 3 literarkritisch und traditionskritisch untersucht. Berlin: De Gruyter. (BZAW 139.)

MITTMANN, S 1978. Komposition und Redaktion von Psalm XXIX. VT 28, 172 194.

MITTMANN, S 1980. Aufbau und Einheit des Danklieds Psalm 23. ZThK 77, 1-23.

MULDER, M J 1987. Koningen, Deel I. Kampen: Kok. (COT.)

MULDER, M J 1989. Salomo's tempel en JHWH's exclusiwiteit. (Rede uitgesproken op 20 Januari 1989 ter gelegenheid van het afscheid als hoogleraar in de Godgeleerdheid aan de Rijsuniversiteit te Leiden). Leiden: Rijksuniversiteit Leiden.

NOORT, E 1989. Exegese van het Oude Testament: Een zwerftocht. GThT 89, 222.

PRINSLOO, WS 1979. Die metodiek van eksegese: 'n Diskussie. NGTT 10/3, 201210.

RICHTER, W 1971. Exegese als Literaturwissenschaft: Entwurf einer alttestamentliche Literaturheorie und Methodologie. Göttingen: Vandenhoeck.

TALSTRA, E, POSTMA F \& VAN ZWET, HA 1981. Deuterojesaja proewe van automatische teksverwerking ten dienste van die eksegese. Amsterdam: VU Boekhandel.

TALSTRA, E, POSTMA F \& VERVENNE, M 1983a. Exodus materials in automatic text processing, Part I: Morphological, syntactical and literary case studies. Amsterdam: VU Boekhandel.

TALSTRA, E, POSTMA, F \& VERVENNE, M 1983b. Exodus materials in automatic text processing, Part II: Concordance. Amsterdam: VU Boekhandel.

TALSTRA, E 1987. Het gebed van Salomo: Synchronie en diachronie in de kompositie van I Kon 8:14-61. Amsterdam: VU Boekhandel.

TALSTRA, E 1989. Grammar and prophetic texts: Computer-assisted syntactical research in Isaiah, in Vermeylen J (ed), The book of Isaiah: Le livre d'Isaie. Les Oracles et leurs relectures unité et complexité de l'ouvrage, 83-91. Leuven: University Press. (BEThL LXXXI.) 